\title{
Covid-19 Induced Adoption of Online Teaching by School Teachers in India
}

\author{
Rajni Khokher \\ District Institute of Education and Training (DIET), Panchkula, INDIA \\ Email id: rajnilohan@gmail.com
}

\begin{abstract}
This paper investigates the adoption of online teaching by schoolteachers in India, and the factors facilitating such adoption in the context of Covid-19 pandemic. The sample consisted of 18 schools' teachers teaching in different schools in Panchkula (Haryana), India. The study adopts a qualitative approach; one-hour in-depth interviews were carried out with the surveyed respondents. Results indicated the important structural changes that are taking place in India regarding the roles and responsibilities of teachers across every teaching levels. Important insights were obtained about factors responsible, challenges faced, and the benefits achieved as a result of adoption of online teaching. Respondents also reported the support of their spouses, institution, and children which helped them in this transition from actual classroom teaching to virtual classroom teaching during the Covid-19 pandemic whereby successive lockdowns were imposed by the governments across countries to mitigate its impact. Respondents perceived the crisis created by Covid-19 pandemic as the most significant reason to adopt onlineteaching. A better understanding of issues pertaining to the adoption of online teaching will contribute to the development of new futuristic educational programs and policies.
\end{abstract}

KEYWORDS: Online-Teaching, Covid-19, Qualitative Approach, India

\section{INTRODUCTION}

The Covid-19 pandemic extensively impacted the entire world in every possible segment be it industries, businesses, travelling, education, day-to-day working, lifestyles, health system, employment, and financial systems. A large number of people lost their jobs, family members, education and much more. The governments across countries have taken various steps to control the spread of this pandemic some of the most prominent included the restrictions imposed on movements outside homes, maintenance of social distancing, and closure of almost all the institutions, factories, schools, colleges, offices, cinema halls, parks, gymnasium, and shops. The pandemic mitigation related steps have impacted education the most in India where the physical teaching was the sole teaching mode in the country especially at the school level, consequently, the teachers had no other choice but to adopt online-teaching to keep the learning process going on during this time. Online teaching turned out to be a focal point for the teachers as well as students during the successive lockdowns initiated by governments to combat the spread of the Covid-19 pandemic. In India, various efforts and initiatives were taken by the central and state governments to keep the teaching-learning process going on such as SWAYAM, DIKSHA, e-Adhyayan, MOOCS, e-Pathya, SHAGUN, and Swayam Prabha (Choudhury, 2020). Various measures were also taken to provide online study material to students including the formation of National Repository of Open Educational Resources, and National Digital Library of India (NDLI) (India education Diary, 2020). Not much work has been undertaken on the issues involved in this transition. This study is an attempt to fill this research gap and is guided by the following objectives:

- To ascertain the factors leading to the adoption of online teaching by teachers.

- To explain the modalities involved in the adoption of online teaching.

- To explore the implications based on study results. 


\section{LITERATURE REVIEW}

The concept of online teaching is not new as there are many examples of teaching with the help of machines (projectors, television-lesson) since 1950s but the scale was very limited as compared to classroom teaching (Sarkar, 2020). Another aspect of online teaching is online-learning. University of Toronto, Canada offered the first-ever online course in 1984 followed by University of Phoenix which by offering wholly online courses both for undergraduates and post graduates students became the first educational institution to do so in 1987, and Britain Open University became the first university in the world to begin online distance learning in 1990s. Currently, IGNOU (Indira Gandhi National Open University) in India stands at the first position in terms of largest number of enrolled students where students are being taught trough online-teaching. In currents times, the scope, strength, and scope of online teaching is increasing exponentially due to the better and widespread internet connectivity, availability of smart phones, mobile data, and social media (Mittal, P., 2020). Researchers have investigated the effectiveness of online viz-a-viz offline teaching in terms of potential to transform the scope of higher studies by providing more opportunities to the students at a lower cost (Yadav et. al., 2018, 2021), however, some of them have raised concerns regarding the negative pedagogical outcomes due to widespread adoption of online learning (Allen \& Seaman, 2014). Many of the researchers have also proposed that the learning outcomes are different in online and offline teaching (Jahng et al., 2007, Chakraborty et. al., 2021). Few studies have suggested that students favour the online teaching, for example, Young (2006) has investigated students' views on online teaching on the bases of data collected from 199 online students. Majority of the students agreed that effective teachers are easily identifiable as they provide flexibility in teaching schedules, provide structured information, more interactive, work hard, involved actively, and establish trusting relationships with the students.

\section{RESEARCH METHODS}

\subsection{Sample and Procedures}

This study makes use of qualitative approach to get an in depth understanding of teachers' adoption of online teaching. Semi-structured in-depth interviews of trained teachers were conducted in Panchkula (Haryana), India. The surveyed respondents were chosen through snowball sampling technique. Initially, 30 teachers teaching in different schools were approached to be part of this study, however, the final sample comprised of 18 of them as they met the underlined selection criterion and were willing give interviews. Informed consent of all the respondents was obtained in the beginning. The surveyed sample consisted to seven government school and eleven private school teachers across ages ranged between 35 and 55. Majority of the respondents were females (55\%). The sample consists of teachers teaching at primary level (22\%), middle level (17\%), secondary level (28\%) and senior secondary level (33 $\%)$. Maximum respondents belonged to urban areas and highly qualified $(72 \%)$. Interviews were scheduled telephonically and conducted at the respondents' residence during January 2022. Each interview lasted for 1 to 1.30 hours. A brief description of participants' demographics appears in Table 1.

Table 1: Sample

\begin{tabular}{|c|l|l|l|l|l|}
\hline & $\begin{array}{l}\mathrm{N}= \\
18\end{array}$ & $\%$ & Characteristics & $\begin{array}{l}\mathrm{N}= \\
18\end{array}$ & $\%$ \\
\hline Age (Yrs) & & & Teaching Level & & \\
\hline $35-40$ & 4 & 22 & Primary (upto class 5) & 4 & 22 \\
\hline $40-45$ & 8 & 44 & Middle (class 6-8) & 3 & 17 \\
\hline $45-50$ & 3 & 17 & Secondary (class 9- 10) & 5 & 28 \\
\hline $50-55$ & 3 & 17 & Senior Secondary (class 11- & 6 & 33 \\
& & & Residential Area & & \\
\hline Gender & & & Urban & 6 & 33 \\
\hline Male & 8 & 44 & 12 & 67 \\
\hline Female & 10 & 55 & & & \\
\hline & & & Highest Education Degree & & \\
\hline School & & & Graduation & 5 & 28 \\
\hline Govt. & 7 & 39 & Post-Graduation and Above & 13 & 72 \\
\hline Private & 11 & 61 & ran & & \\
\hline
\end{tabular}

\section{DATA ANALYSIS}

The interview data was analyzed by using the Grounded theory developed by Strauss and Corbin (1994) who they have defined as "a non-mathematical process of interpretation, carried out for the purpose of discovering concepts and relationships in raw data and then organizing these into a theoretical explanatory scheme" (Ralph et al., 2015). This theory makes use of inductive approach for data analysis.

The process of data analysis entails the following steps: (i) coding- data analysis process started with the codification of each interview line by line; (ii) memoing - whereby each information that was emerged during the codification stage was identified and segregated under a distinct category; (iii) sorting - at this stage meomos were sorted on the bases of commonality; and (iv) final results - at this stage final results were enumerated in the light of existing literature.

\section{Results}

Study results were enlisted as per the themes that have been identified during the analysis process. Four main categories identified were: pre-preparedness, facilitating factors, challenges, and future prospects.

\section{Pre-preparedness}

The interviews indicated that the pandemic generated pressure to shift from offline-teaching to onlineteaching was too totally unpredictable and sudden. A teacher said:

"Suddenly every newspaper and television channels started talking about the spread of the deadly Coronavirus, lockdowns, curfews, and shutting down of everything including schools, colleges, and offices. Then came the confusion with the directives from their 
institution to start teaching online without delay for which they were not at all prepared and equipped"

\section{Facilitating Factors}

These are the factors that have been instrumental in the adoption of online-teaching during the Covid-19 pandemic such as institutional support in the form of webinars, you-tube videos and other social-media platforms, smart phones, Internet, friends, colleagues, family members including children. For example, a teacher teaching in a private school said:

"Although the pandemic has created a critical situation regarding teaching and the atmosphere of uncertainty, however, my school conducted many webinars for the teachers and provided round the clock technical support to take online classes".

Another teacher has supplemented the aforementioned views:

"Videos available on you-tubes were very handy and immensely helped me in taking online classes. Whatsapp groups were also useful in giving important directions to students and parents apart from resolving their doubts"

The respondents also talked about the support they received from their families, friends, and social groups:

"Previous to Covid, I was using my phone only for limited purposes: making-receiving phone calls, Whatsapp, emails. Suddenly with the help of my friends and children, I started taking my classes on phone"

\section{CHALLENGES}

The respondents irrespective of the subjects they teach reported various challenges they have faced in the online-teaching at their as well as students' end such as poor Internet connectivity, lack of knowledge to use computers, non-availability of smart phones, nonavailability of noise-free space in their homes, lack of direct interaction, low concentration, hearing issues, lack of active evaluation system. Teachers teaching different subjects have said:

"Although I learnt how to use deliver my lessons online through Google Meet but most of my students do not have personal smart phones, hence, they missed most of my classes"

"I teach mathematics which needs regular practice in class and at home. On online teaching most of the students keep their camera off and do not respond in case they unable to understand a new concept as in online teaching I cannot check their class work or homework notebooks frequently"

"I teach English. I used to ensure that students speak in the language in my class which I cannot do online as many a time students' say that their speakers have issues or the internet connectivity is low"

\section{FUTURE PROSPECTS}

Majority of the respondents expressed their apprehensions about the future of online-teaching in India. The reasons cited by them include: poor and uneducated parents, lack of basic infrastructure in terms of Wi-Fi connectivity, electricity, and home-space, lack of active student-teacher participation, emerging health issues such as weight gain, depression, online bullying, mass copying and cheating in online examination. A teacher said:

"I take every effort to make my class interesting, however, after class the students' have no assistance in their homework completion from parents as a result they copy from each other or from web-sites and submit which is rather detrimental to the learning"

"Students are becoming more aggressive as they are not getting proper chances to socialize within the class"

"Students are becoming less attentive in class as they are not being properly evaluated"

\section{CONCLUSIONS AND FUTURE RESEARCH}

India is an emerging capitalistic economy where too many socio-economic disparities exist at many fronts. The National Education Policy, NEP 2020 also emphasizes on teaching in a blended mode, however, the conclusion of this study reveals all the possible difficulties in this process. The policy makers and different stakeholders should take note of these results before executing the NEP 2020. As the respondents indicated that active engagement of students in onlineclasses is an important issue, steps must be taken to modify the syllabus accordingly to keep their interest in the virtual classrooms.

Another significant point raised by the teachers is the lack of students' concentration in the class, for this each class duration may be of less time duration and side by side students may be encouraged and guided to adopt some hobbies also. For cyber-crime related protection, webinars may be conducted to make the students aware about these issues. Financial help may also be provided to the needy students who lack the basic infrastructure, i.e., smart phones, laptop/desktop, Internet connection/mobile data, and electricity. The results of this study may be extended by using a quantitative approach by collecting data from a greater number of teachers. Also, the students may also be included in future studies to make them more reliable, practical, and useful.

\section{REFERENCES}

Allen, I. E., and Seaman, J. (2014), "Grade change: Tracking online education in the United States", Babson Park, Massachusetts: BABSON Survey Research Group.

Baran, E., Correiab, A-P., and Thompsonb, A. (2011), "Transforming online teaching practice: critical analysis of the literature on the roles and competencies of online teachers", Distance Education, 32 (3), pp. 421-439. 
Chakraborty, P., Mittal, P., Gupta, M. S., Yadav, S., \& Arora, A. (2021). Opinion of students on online education during the COVID-19 pandemic. Human Behavior and Emerging Technologies, 3(3), 357-365. https://doi.org/10.1002/hbe2.240

Choudhury, T. (2020), “Top 8 government eLearning platforms for students', https://www.abpeducation.com/educationtips/top-8-government-elearning-platforms-for-students1.1192917

India Education Diary (2020), "Ministry of education has taken several initiatives to ensure studies of school going children during COVID-19 pandemic - education minister", https://indiaeducationdiary.in/ministry-of-education-hastaken-several-initiatives-to-ensure-studies-of-school-goingchildren-during-covid-19-pandemic-education-minister/, September 2020 .

Jahng, N., Krug, D., and Zhang, Z. (2007), "Student achievement in online distance education compared to face-to-face education". European Journal of Open, Distance and ELearning. http://www.eurodl.org/index.php?article=253.

Mittal, P. (2020). A multi-criterion decision analysis based on PCA for analyzing the digital technology skills in the effectiveness of government services. In 2020 International Conference on Decision Aid Sciences and Application, DASA $2020 \quad$ (pp. 490-494). IEEE. https://doi.org/10.1109/DASA51403.2020.9317241

Ralph, N., Birks, M., and Chapman, Y. (2015), "The methodological dynamism of grounded theory" (PDF). International Journal of Qualitative Methods, 14 (4). 160940691561157. doi:10.1177/1609406915611576

Sarkar, S. (2020), “A brief history of online education”, https://adamasuniversity.ac.in/a-brief-history-of-onlineeducation/

Yadav, S., Chakraborty, P., \& Mittal, P. (2021). Designing Drawing Apps for Children: Artistic and Technological Factors. International Journal of Human-Computer Interaction, $1-15$. https://doi.org/10.1080/10447318.2021.1926113

Yadav, S., Chakraborty, P., Meena, L., Yadav, D., \& Mittal, P. (2021). Children's interaction with touchscreen devices: Performance and validity of Fitts' law. Human Behavior and Emerging Technologies, 3(5), 1132-1140. https://doi.org/10.1002/hbe2.305

Yadav, S., Chakraborty, P., Mittal, P., \& Arora, U. (2018). Children aged 6-24 months like to watch YouTube videos but could not learn anything from them. Acta Paediatrica, International Journal of Paediatrics, 107(8), 1461-1466. https://doi.org/10.1111/apa.14291

Young, S. (2006), "Student Views of Effective Online Teaching in Higher Education", American Journal of Distance Education, $20 \quad$ (2), pp. 77, DOI: $10.1207 /$ s15389286ajde2002_2 